\title{
Correlation of Cervical Vertebral Bone Age and Demirjian's Stages of Dental Maturation for Lower Left Permanent Canine and Second Molar
}

\author{
Narayan Kulkarni ${ }^{1}$, Bhavna Dave ${ }^{2}$
}

\begin{abstract}
Aim: To evaluate and correlate cervical vertebral bone age(CVBA) and Demirjian's stages of dental maturation for lower left permanent canine(CMS) and second molar (MMS).

Materials and methods: A cross-sectional radiographic study was conducted on 264 participants with age group of 7-18 years who were further categorized into six subgroups having an interval of 2 years chronologic age. The CVBA, CMS, and MMS were assessed for the same patient. The assessment of CVBA of the participants involved in the study was derived from the equation given by Mito et al. The height and width of the 3rd and 4th cervical vertebra was measured with the help of IC measure software. The dental maturation was assessed as per the morphologic classification method given by Demirijian. Analysis of variance (ANOVA), Tukey's multiple comparisons and Spearman's correlation coefficient was utilized to determine the significance and correlation between the age groups, CVBA, CMS, and MMS. The multiple comparison levels were set at 0.05 level of significance.

Results: Significantly different CVBA was observed among each individual stage of CMS and MMS. Significant changes in the dimensions of the cervical vertebra were observed when the dental maturation stage progressed from $\mathrm{F}$ to $\mathrm{G}$ and $\mathrm{G}$ to $\mathrm{H}$ stage.

Conclusion: Chronologic age had a moderate correlation with CVBA. CVBA was significant for all the stages of maturation of CMS and MMS. Females revealed a higher level of maturation. A significant difference in the vertebral bone age was observed in the transition of stage $F$ to $G$ and $\mathrm{G}$ to $\mathrm{H}$ of dental maturation of canine and molar. Both CMS and MMS revealed a significant strong positive correlation with CVBA.

Clinical significance: Cervical vertebral bone age can be utilized as an adjunct in identifying the stages of dental maturation of lower left permanent canine and second molar.

Keywords: Cervical vertebral bone age, Demirjian's method, Dental maturation.

The Journal of Contemporary Dental Practice (2019): 10.5005/jp-journals-10024-2541
\end{abstract}

\section{INTRODUCTION}

S exual maturation characteristics, height, weight, and skeletal development have been routinely used to identify and analyze the stages of growth of an individual. ${ }^{1}$ The skeletal maturity assessment was the most reliable method to identify the stages of growth. ${ }^{2}$ For treatment planning in orthodontics, evaluation of skeletal maturation has significance since skeletal maturation is an integral part of a patient's pattern of facial growth and development. ${ }^{3}$ The complexity in the identification of morphology of the various bones involved in the analysis of the hand wrist radiographs and the need to take an additional radiograph declined the utility of the hand wrist radiographs as a means for determination of skeletal maturity.

Majority of the studies utilized Demirjian, Nolla, Hassel and Farman, Greulich and Pyle method for assessment of skeletal and dental maturity to identify and diagnose the present stage of physical maturity of an individual. It was observed that CMS and MMS was routinely employed for determining the skeletal maturation. ${ }^{4-6}$

Literature suggests that the repeatability of morphologic identification for the estimation of the growth status of the child also had some drawbacks. The amount of training in the visual assignment of the CVMI stage also has a reflective effect on the staging of CVMI for determining the growth status of the child. Hence further studies were based on deriving regression equation for CVMI. Regression formula was first given by Mito et al. ${ }^{7}$ He derived skeletal age which is based on ratios of widths and heights of cervical vertebrae C3 and C4. Hence an attempt
${ }^{1}$ Department of Orthodontics and Dentofacial Orthopedics, KM Shah Dental College and Hospital, Sumandeep Vidyapeeth, Vadodara, Gujarat, India

${ }^{2}$ Department of Paedodontics and Preventive Dentistry, KM Shah Dental College and Hospital, Sumandeep Vidyapeeth, Vadodara, Gujarat, India

Corresponding Author: Narayan Kulkarni, Department of Orthodontics and Denotfacial Orthopedics, KM Shah Dental College and Hospital, Vadodara, Gujarat, India, e-mail: drorthonaru@gmail.com

How to cite this article: Kulkarni N, Dave B. Correlation of Cervical Vertebral Bone Age and Demirjian's Stages of Dental Maturation for Lower Left Permanent Canine and Second Molar. J Contemp Dent Pract 2019;20(4):471-475.

Source of support: Nil

Conflict of interest: None

was made to evaluate and correlate CVBA with Demirjian's stages of dental maturation for lower left permanent canine (CMS) and second molar (MMS).

\section{Materials AND METHOdS}

A total of 264 patients with an age range of 7-18 years were selected from the outpatient department (OPD) of the department who were willing to undergo orthodontic treatment.

A prospective cross-sectional design was utilized to conduct the study. Convenience simple random sampling technique was utilized for the selection of participants included in the study. The study was conducted in the department of orthodontics

(c) The Author(s). 20190pen Access This article is distributed under the terms of the Creative Commons Attribution 4.0 International License (https://creativecommons. org/licenses/by-nc/4.0/), which permits unrestricted use, distribution, and non-commercial reproduction in any medium, provided you give appropriate credit to the original author(s) and the source, provide a link to the Creative Commons license, and indicate if changes were made. The Creative Commons Public Domain Dedication waiver (http://creativecommons.org/publicdomain/zero/1.0/) applies to the data made available in this article, unless otherwise stated. 
and dentofacial orthopedics, KM Shah Dental College, and Hospital, Sumandeep Vidyapeeth, Piparia, Gujrat, India. Lateral cephalogram and OPG of the participant included in the study were collected on the same day. All the Cephalograms and OPGs of participants included in the study were taken from Kodak 8000 c digital panoramic and cephalometric system. A fixed distance of 5 feet with an exposure time of 1 second, $78 \mathrm{KVP}$ and 12-15 MA were maintained during the exposure of the radiographic film. A participant information sheet was provided to the patient and informed consent was obtained from all the patients included in the study. Patients who had no history of medical or surgical disease affecting the presence and development of all teeth till second molars were included in the study. Patients with a history of serious illness, systemic disease, bone disease or deformities, trauma or disease to face, and/or neck, etc. were excluded from the study.

These 264 participant's lateral cephalograms and OPGs were further subdivided into 6 groups having a chronologic age group interval of 2 years each ( 7 years 1 month to 8 years 11 months, 9 years 1 month to 10 years 11 months, 11 years 1 month to 12 years 11 months, 13 years 1 month to 14 years 11 months, 15 years to 16 years 11 months, 17 years to 18 years 11 months). Each group comprised of 44 cephalograms having an equal gender distribution.

The staging of lower left permanent canine and the second molar was based on Demirjian Index. Both lower left permanent canine and second molars of an individual patient were traced on a tracing paper with the help of OPG, (Fig. 1A). The traced teeth were matched to the most nearing stage of maturation, (Fig. 1B). The CVBA was calculated as per the regression equation is given by Mito et al. ${ }^{7}$ The measurements of the height and width of the third and fourth cervical vertebra was measured by the principal investigator (NK) with the help of 'IC measure' software (Germany), (Fig. 2). The co-investigator (BD) who recorded the CVBA was blinded for the staging of lower left permanent molar and canine. All the measurements of third and fourth cervical vertebrae and the staging of permanent lower left canine and the second molar was recorded on the Microsoft Excel sheet and subjected to statistical analysis.

\section{Statistical Analysis}

Mean and standard deviation of age and cervical vertebral bone age were calculated. ANOVA test was utilized to determine the significance between age groups, gender, CVBA, CMS, and MMS. Tukey's post hoc test was also used to compare the importance of CVBA, CMS, and MMS. Spearman's correlation coefficient was utilized to derive the correlation among CVBA to CMS and MMS. The statistical analysis was carried out with the help of SPSS 21 version software.

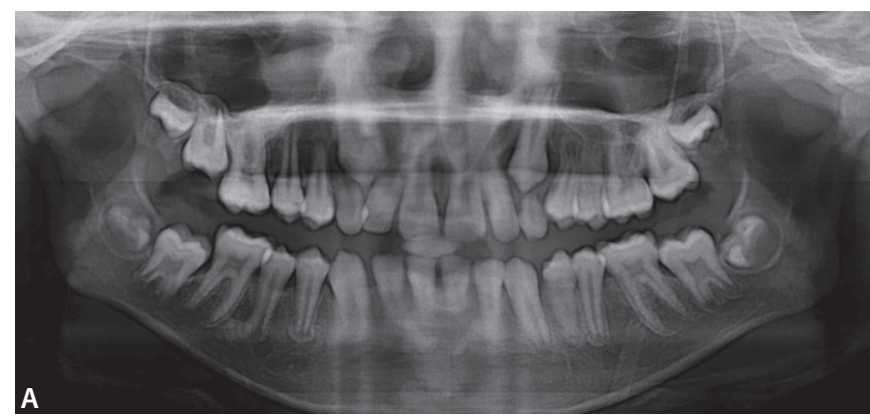

\section{Observation and results}

When the vertebral bone age was evaluated on an overall, it was observed that as the chronologic age increased, the CVBA also increased. Significant morphologic changes of the third and fourth cervical vertebra were observed between the age groups of 1315 and 15-17 years' age group of individuals (Table 1). Among both males and females, it was observed that the change in the dimensions of the third and fourth cervical vertebra was gradual until 13 years. A major difference was observed in the age group of 13 to 15 years (Table 1 ).

The CVBA was also evaluated as per the CMS and MMS. It was observed that as the CMS and MMS increased, the CVBA also increased. A higher value of CVBA was observed with MMS. There was a statistically significant difference observed when the CVBA was compared as per the stages of CMS and MMS (Table 2).

The frequency of distribution of maturation stages of lower left permanent canine and the second molar was also analysed. Among various stages of maturation, a frequency distribution of $43.6 \%$ for stage $\mathrm{H}$ was observed. However, stage $\mathrm{E}$ and $\mathrm{F}$ had equal distribution representing $16.3 \%$ of the total participants (Table 3 ).

The appraisal of maturation of lower left permanent second molar revealed a maximum number of participants with stage $\mathrm{H}$ having a frequency distribution of $29.2 \%$ while the lowest number of participants were seen in stage $\mathrm{C}(0.8 \%)$ (Table 4$)$.

The CVBA was also evaluated as per the CMS and MMS. It was observed that as the CMS and MMS increased, the CVBA also increased. A higher value of CVBA was observed with MMS. There was a statistically significant difference observed when the CVBA was compared as per the stages of CMS and MMS (Table 2).

The CMS and MMS were also compared for the CVBA, a significant difference was observed, with maturation stages of $F$ to $\mathrm{G}$ and $\mathrm{G}$ to $\mathrm{H}$ as shown in Graphs 1 and 2.

The correlation between CVBA and CMS and MMS was appraised. Both canine and second molar revealed a strong positive relationship. However, the canine revealed a higher value in comparison to the second molar.

\section{Discussion}

Each individual has its rhythm of growing, and according to it, growth can be rapid, normal or late. The most useful method to evaluate biological maturity is the estimation of the skeletal age because the changes that bones experience during their maturation process are very similar in all individuals and each ossification center goes through many morphological changes that can be easily identified. ${ }^{8}$

It has long been recognized that an individual's chronologic age does not necessarily correlate well with his maturation age.

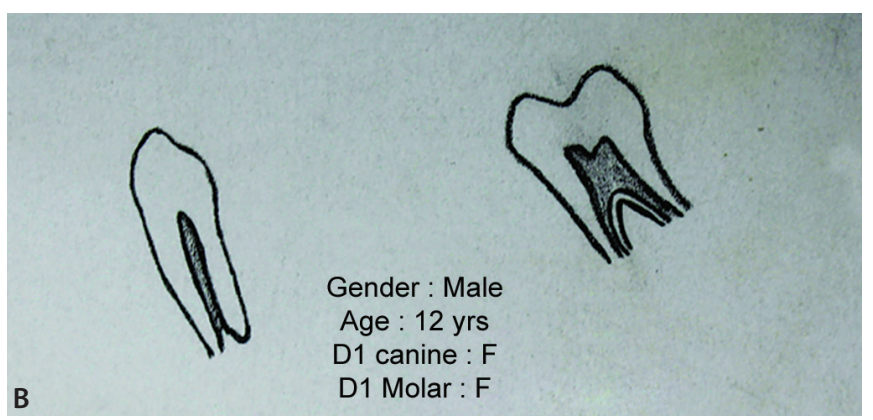

Figs $1 \mathrm{~A}$ and B: Illustration for determining the Demirjian Stage of maturation of lower left permanent canine (CMS) and second molar (MMS); (A) Panoramic radiograph (OPG); (B) Tracing of canine and second molar. 


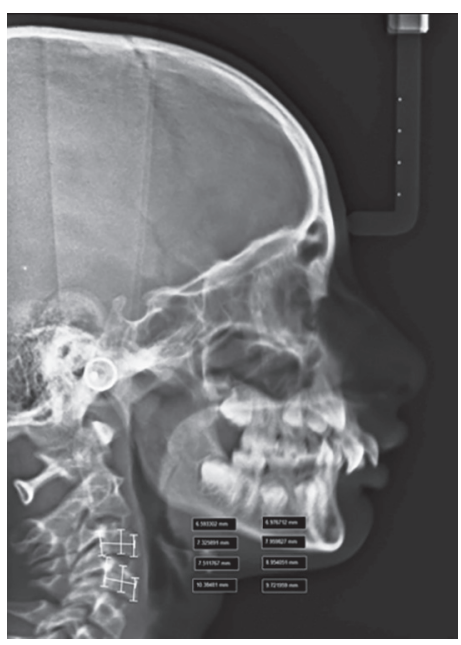

Fig. 2: Illustration of measurements used to determine cervical bone age

Skeletally, one may be retarded or advanced in various degrees of deviation from the actual chronological age. ${ }^{9,10}$

The hand-wrist radiograph is one of the most reliable radiographs to assess skeletal development. However, due to the complex anatomy and need for an extra radiograph, analysis of the skeletal maturity indicators such as hand wrist and cervical vertebra maturation index have various shortcomings. Hence the decline of utilization of the hand wrist radiograph and the increase in cervical vertebrae maturation for growth assessment has become pragmatic. ${ }^{8}$

Many investigators have suggested that the size and shape of the cervical vertebrae change from birth to full maturity at each level of skeletal development. ${ }^{2}$ Baccetti et al. showed that only the shape changes of $C 2, C 3$, and C4 were enough to show skeletal maturation. ${ }^{11}$ Further Perinetti et al. suggested that regular training is necessary to obtain high diagnostic accuracy and intra-rater repeatability in the visual assignment of the CVMI stages. ${ }^{12}$
Literature suggested that digital methods of evaluation of cervical vertebra can be employed in the analysis of maturation of CVMI. The ability of the software to measure the dimensions of the cervical vertebra in decimals enhanced the diagnostic accuracy of the CVBA of an individual. Hence the digital method of assessment was employed.

Kumara et al., Perinetti et al. and Kiran et al. suggested that the CMS and MMS can be used for assessment of growth maturation of an individual. ${ }^{2,12,13}$

It was observed in the literature that no study correlated the CVBA to the CMS and MMS. Hence this study was carried out to evaluate and compare CVBA with CMS and MMS.

Table 1: Cervical vertebral bone age distribution as per age group and gender

\begin{tabular}{lllllll}
\hline \multicolumn{7}{c}{ Calculated CVBA } \\
\hline \multirow{4}{*}{ Gender } & Age group & $N$ & Minimum & Maximum & Mean & $\begin{array}{l}\text { Std. } \\
\text { deviation }\end{array}$ \\
\hline \multirow{6}{*}{ Male } & 7-9 years & 22 & 9.35 & 12.53 & 11.19 & 1.01 \\
& $9-11$ years & 22 & 10.96 & 14.81 & 12.71 & 1.00 \\
& $11-13$ years & 22 & 10.45 & 16.09 & 12.46 & 1.44 \\
& $13-15$ years & 22 & 10.82 & 19.63 & 15.75 & 2.82 \\
& $15-17$ years & 22 & 14.72 & 19.93 & 17.72 & 1.49 \\
& $17-19$ years & 22 & 16.46 & 21.69 & 18.91 & 1.24 \\
\hline Female & $7-9$ years & 22 & 9.45 & 13.60 & 11.93 & 1.14 \\
& $9-11$ years & 22 & 10.66 & 15.23 & 12.41 & 1.06 \\
& $11-13$ years & 22 & 9.02 & 17.79 & 13.63 & 2.32 \\
& $13-15$ years & 22 & 12.65 & 19.41 & 16.42 & 1.63 \\
& $15-17$ years & 22 & 14.51 & 23.25 & 18.99 & 2.45 \\
& $17-19$ years & 22 & 15.45 & 19.80 & 18.09 & 1.17 \\
\hline
\end{tabular}

Table 2: Cervical vertebral bone age distribution as per maturation stages of canine and second molar

\begin{tabular}{|c|c|c|c|c|c|c|c|c|c|c|c|}
\hline \multirow{2}{*}{$\begin{array}{l}\text { Stage of } \\
\text { maturation }\end{array}$} & $N$ & Mean & $\begin{array}{l}\text { Std. } \\
\text { deviation }\end{array}$ & $N$ & Mean & \multirow{2}{*}{$\begin{array}{l}\text { Std. } \\
\text { deviation }\end{array}$} & \multirow{2}{*}{$\begin{array}{l}\text { Sum of } \\
\text { squares }\end{array}$} & \multirow[b]{2}{*}{$D f$} & \multirow{2}{*}{$\begin{array}{l}\text { Mean } \\
\text { square }\end{array}$} & \multirow[b]{2}{*}{$F$} & \multirow[b]{2}{*}{ Sig. } \\
\hline & & Canin & & & Molar & & & & & & \\
\hline Stage C & - & - & - & 2 & 11.41 & 1.35 & - & - & - & - & - \\
\hline Stage D & 23 & 11.45 & 1.13 & 43 & 11.93 & 1.21 & - & - & - & - & - \\
\hline Stage $E$ & 43 & 12.20 & 1.16 & 45 & 12.90 & 2.01 & 1751.056 & 4 & 437.764 & 108.788 & 0.000 \\
\hline Stage $F$ & 43 & 12.67 & 1.48 & 44 & 13.33 & 2.18 & 1042.216 & 259 & 4.024 & - & - \\
\hline Stage G & 40 & 14.69 & 2.86 & 53 & 16.27 & 3.11 & 2793.272 & 263 & - & - & - \\
\hline Stage H & 115 & 17.78 & 2.19 & 77 & 18.17 & 1.75 & - & - & - & - & - \\
\hline
\end{tabular}

Table 3: Frequency distribution of various stages of maturation of canine

\begin{tabular}{lll}
\hline $\begin{array}{l}\text { Maturation stage of canine } \\
\text { (CMS) }\end{array}$ & Frequency & $\begin{array}{l}\text { Percentage } \\
(\%)\end{array}$ \\
\hline Stage D & 23 & 8.7 \\
Stage E & 43 & 16.3 \\
Stage F & 43 & 16.3 \\
Stage G & 40 & 15.2 \\
Stage H & 115 & 43.6 \\
\hline Total & 264 & 100.0 \\
\hline
\end{tabular}

Table 4: Frequency distribution of maturation stages of second molar

\begin{tabular}{lll}
\hline $\begin{array}{l}\text { Maturation stage of second } \\
\text { molar }\end{array}$ & Frequency & Percentage \\
\hline Stage C & 2 & 0.8 \\
Stage D & 43 & 16.3 \\
Stage E & 45 & 17.0 \\
Stage F & 44 & 16.7 \\
Stage G & 53 & 20.1 \\
Stage H & 77 & 29.2 \\
\hline Total & 264 & 100.0 \\
\hline
\end{tabular}


Kumar, Agarwal, Mehrotra did a study on evaluation of skeletal maturity in North Indian subjects using an objective method based on CVBA and assessment of its reliability as compared to hand wrist radiographic method and found that the process of objectively evaluating skeletal maturation is reliable and can be applied in orthodontic diagnosis and treatment planning. ${ }^{14}$

The mean vertebral bone age of various age groups was 11.56 for 7 years 1 month-8years 11 months, 12.56 for 9 years 1 month-10 years 11 months, 13.04 for 11years 1 month-12 years 11 months, 16.08 for 13 years 1 month-14 years 11 months, 18.36 for 15 years 1 month-16 years 11 months and 18.50 for 17 years 1 month-18 years 11 months for the samples included in this study.

When the vertebral bone maturation was compared among girls and boys, it was found that at the same age, girls showed greater maturation than the boys (Table 1). This suggested that

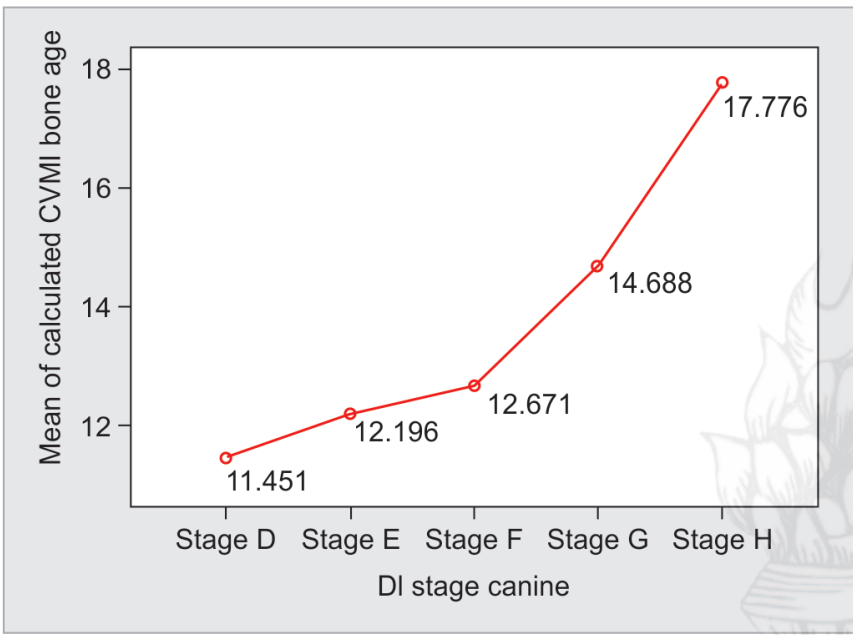

Graph 1: Correlation of cervical vertebral bone age and maturation stages of canine females achieved growth maturation earlier than males. This observation is similar to the study done by Srkoc et al. ${ }^{15}$ On observing the distribution of CVBA as per CMS and MMS it was observed that statistically significant values were obtained when correlated with the transition stages of DI from $F$ to $G$ and $G$ to $H$ in both canine and molar. Stages $G$ and $H$ revealed aCVBAof 14.69 \pm 2.86 and $17.78 \pm 2.19$, respectively. Whereas, the molar revealed a CVBA of $16.27 \pm 3.11$ and $18.17 \pm 1.75$ for stage $G$ and $H$ respectively as shown in Graphs 1 and 2. These results obtained from this study were found to be similar to the results obtained in the study done by Rozylo-Kalinowska et al. ${ }^{16}$

In the study done by Chen J et al. it was found that The Spearman rank-order correlation coefficients between dental maturity and cervical vertebral maturity ranged from 0.391 to 0.582 for girls and from 0.464 to 0.496 for boys $(p<0.05)$. In girls, the

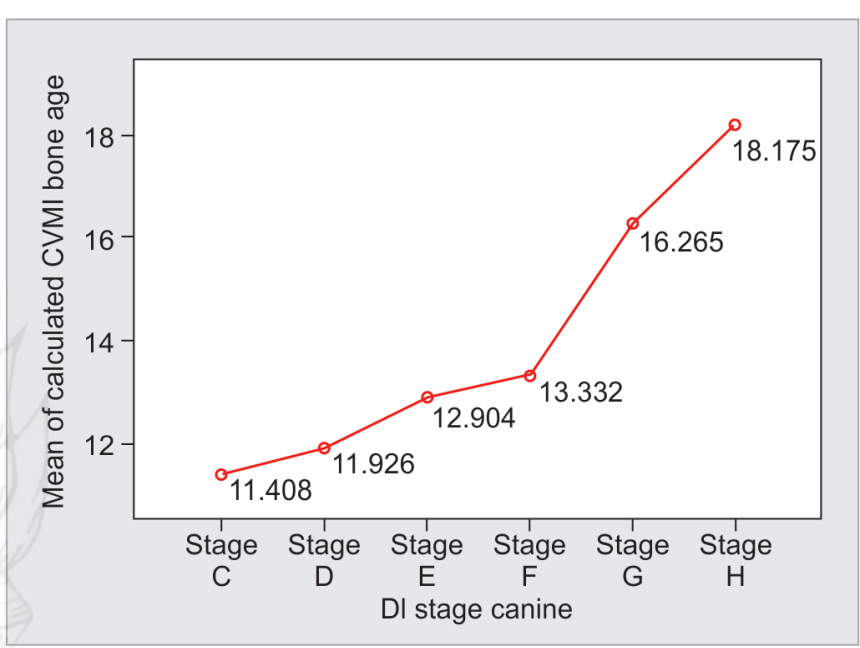

Graph 2: Correlation of cervical vertebral bone age and maturation stages of permanent second molar

Table 5: Correlation between maturation stage of canine, molar and cervical vertebral bone age

\begin{tabular}{|c|c|c|c|c|c|c|}
\hline \multicolumn{6}{|c|}{ Spearman correlations } & \multirow[b]{2}{*}{ Chronologic age } \\
\hline & & & DI Stage canine & Dl stage molar & $\begin{array}{l}\text { Calculated CVMI } \\
\text { bone age }\end{array}$ & \\
\hline \multirow{12}{*}{ Spearman's RHO } & \multirow{3}{*}{ DI stage canine } & $\begin{array}{l}\text { Correlation } \\
\text { coefficient }\end{array}$ & 1.000 & $0.887^{* *}$ & $0.769^{* *}$ & 0.496 \\
\hline & & $p$ value & - & 0.000 & 0.000 & 0.5 \\
\hline & & $\mathrm{N}$ & 264 & 264 & 264 & 264 \\
\hline & \multirow{3}{*}{ DI stage molar } & $\begin{array}{l}\text { Correlation } \\
\text { coefficient }\end{array}$ & $0.887^{* *}$ & 1.000 & $0.734^{* *}$ & 0.437 \\
\hline & & $p$ value & 0.000 & - & 0.000 & 0.5 \\
\hline & & $\mathrm{N}$ & 264 & 264 & 264 & 264 \\
\hline & \multirow{3}{*}{$\begin{array}{l}\text { Calculated CVMI } \\
\text { bone age }\end{array}$} & $\begin{array}{l}\text { Correlation } \\
\text { coefficient }\end{array}$ & $0.769^{* *}$ & $0.734^{* *}$ & 1.000 & 0.345 \\
\hline & & $p$ value & 0.000 & 0.000 & - & 0.5 \\
\hline & & $\mathrm{N}$ & 264 & 264 & 264 & 264 \\
\hline & \multirow{3}{*}{$\begin{array}{l}\text { Chronological } \\
\text { age }\end{array}$} & $\begin{array}{l}\text { Correlation } \\
\text { coefficient }\end{array}$ & 0.496 & .437 & 0.345 & 1.000 \\
\hline & & $p$ value & 0.5 & 0.5 & 0.5 & - \\
\hline & & $\mathrm{N}$ & 264 & 264 & 264 & 264 \\
\hline
\end{tabular}

${ }^{* *}$ Correlation is significant at the 0.01 level (2-tailed). 
mandibular second molar had the highest, and the canine revealed the lowest correlation. In boys, the canine had the highest and the first premolar the lowest correlation. ${ }^{17}$

In this present study, CVBA was also correlated with CMS and MMS. The correlation coefficient for DI stage canine and CVMI bone age was 0.769 and for second molar it was 0.734 ( $p \leq 0.01$ ) (Table 5). However, the correlation between the two may not hold as the skeletal age, and chronological age was found to have a moderate non-significant co-relation (Table 5).

The results of the present study should be interpreted cautiously as the design of the study was cross-sectional which accepts the limitation of investigating the growth of an individual. It is also observed that only subjective method of evaluation of maturation stages of canine was observed which is subject to one's own opinion of recognizing the traits. A further longitudinal study can be planned to derive an objective method that could help in identifying the level of dental maturation.

\section{Conclusion}

Chronologic age had a moderate correlation with CVBA. The CVBA was significant for all the stages of maturation of CMS and MMS. Females revealed a higher level of maturation. A substantial difference in the vertebral bone age was observed in the transition of stage $F$ to $G$ and $G$ to $H$ of dental maturation of canine and molar. Both CMS and MMS revealed a significant strong positive correlation with CVBA. Digital appraisal of vertebral measurements enhanced the precision of determining the CVBA.

\section{Clinical significance}

Cervical vertebral bone age can be utilized as an adjunct in identifying the stages of dental maturation of lower left permanent canine and second molar.

This research was approved by the Research and Ethics Committee of Sumandeep Vidyapeeth University (SVIEC/on/dent/ $\mathrm{PhD} / 15004)$.

\section{References}

1. Hassel B, Farman AG. Skeletal maturation evaluation using cervical vertebrae. Am J Orthod. Dentofac Orthop 1995;107:58-66

2. Kiran S, Sharma VP, Tandon P, et al. To establish the validity of dental age assessment using Nolla's method on comparing with skeletal age assessed by hand-wrist radiographs. J Orthod Res 2013;1:11-15
3. Suri S, Prasad C, Bryan T et al. Longitudinal comparison of skeletal age determined by the Greulich and Pyle method and chronologic age in normally growing children, and clinical interpretations for orthodontics. Am J Orthod Dentofac Orthop 2013;143:50-60.

4. Goyal S, Goyal S, Gugnani N. Assessment of skeletal maturity using the permanent mandibular canine calcification stages. J Orthod Res 2014;2:11-16.

5. Uysal T, Sari Z, Ramoglu S, et al. Relationship between dental and skeletal maturity in Turkish subjects. Angle Orhod 2004;74(5):657-664.

6. Larry J Green. The interrelationships among height, weight and chronological, dental and skeletal ages. Angle Orhod. 1961;31(3):189193.

7. Mito $\mathrm{T}$, Sato $\mathrm{K}$, Mitani H. Cervical vertebral bone age in girls. Am J Orthod Dentofacial Orthod 2002;122:380-385.

8. Caldas MP, Ambrosano GM, HaiterNeto F. Computer-assisted analysis of cervical vertebral bone age using cephalometric radiographs in Brazilian subjects. Brazilian oral research. 2010;24(1):120-126.

9. Bambha JK. Longitudinal cephalometric roentgenographic study of face and cranium in relation to body height. The Journal of the American Dental Association 1961;63(6):776-799.

10. Fishman LS. Chronological versus skeletal age, an evaluation of craniofacial growth. The Angle Orthodontist 1979;49(3):181-189.

11. Baccetti T, Franchi L, McNamara Jr JA. An improved version of the cervical vertebral maturation (CVM) method for the assessment of mandibular growth. The Angle Orthodontist 2002;72(4): 316-323.

12. Perinetti G, Caprioglio A, Contardo L. Visual assessment of the cervical vertebral maturation stages: A study of diagnostic accuracy and repeatability. The Angle Orthodontist. 2014 Mar 25;84(6):951-956.

13. Kumar S, Singla A, Sharma R, et al. Skeletal maturation evaluation using mandibular second molar calcification stages. The Angle Orthodontist 2011;82(3):501-506.

14. Kumar S, Agarwal N, Mehrotra AK. Evaluation of skeletal maturity in North Indian subjects using an objective method based on cervical vertebral bone age and assessment of its reliability as compared to hand wrist radiographic method. Journal of Indian Orthodontic Society 2016;50(1):3.

15. Srkoc T, Mestrovic S, Anic-Milosevis $\mathrm{S}$, et al. Association between dental and skeletal maturation stages in Croatian subjects. Actaclinica Croatica 2015;54(4.):445-452.

16. Rozylo-Kalinowska I, Kolasa-Rączka A, Kalinowski P. Relationship between dental age according to Demirjian and cervical vertebrae maturity in Polish children. The European Journal of Orthodontics 2010;33(1):75-83.

17. Chen J, Hu H, Guo J, et al. Correlation between dental maturity and cervical vertebral maturity. Oral Surgery, Oral Medicine, Oral Pathology, Oral Radiology, and Endodontology. 2010 Dec 1;110(6):777783. 